OPEN ACCESS

Edited by:

Pierina Visciano,

Università di Teramo, Italy

Reviewed by:

Sunil D. Saroj,

Symbiosis International University,

India

Vivek K. Bajpai,

Dongguk University Seoul,

South Korea

Katarzyna Anna Marchwińska,

Poznań University of Economics,

Poland

*Correspondence:

Naveen K. Kalagatur

knaveenkumar.kalagatur@yahoo.co.in

Venkataramana Mudili

ramana.micro@gmail.com

Specialty section:

This article was submitted to

Food Microbiology,

a section of the journal

Frontiers in Microbiology

Received: 14 September 2017

Accepted: 18 June 2018

Published: 31 July 2018

Citation:

Kalagatur NK, Kamasani JR

Siddaiah C, Gupta VK, Krishna K and

Mudili V (2018) Combinational

Inhibitory Action of Hedychium

spicatum L. Essential Oil and

$\gamma$-Radiation on Growth Rate and

Mycotoxins Content of Fusarium

graminearum in Maize: Response

Surface Methodology.

Front. Microbiol. 9:1511.

doi: 10.3389/fmicb.2018.01511

\section{Combinational Inhibitory Action of Hedychium spicatum L. Essential Oil and $\gamma$-Radiation on Growth Rate and Mycotoxins Content of Fusarium graminearum in Maize: Response Surface Methodology}

\author{
Naveen K. Kalagatur ${ }^{1 *}$, Jalarama R. Kamasani², Chandranayaka Siddaiah ${ }^{3}$, \\ Vijai K. Gupta ${ }^{4}$, Kadirvelu Krishna ${ }^{5}$ and Venkataramana Mudili ${ }^{5 *}$
}

${ }^{1}$ Food Microbiology Division, Defence Food Research Laboratory, Mysuru, India, ${ }^{2}$ Freeze Drying and Processing Technology Division, Defence Food Research Laboratory, Mysuru, India, ${ }^{3}$ Department of Biotechnology, University of Mysore, Mysuru, India, ${ }^{4}$ Department of Chemistry and Biotechnology, Tallinn University of Technology, Tallinn, Estonia, ${ }^{5}$ DRDO-BU-Centre for Life Sciences, Coimbatore, India

Nowadays, contamination of agricultural commodities with fungi and their mycotoxins is one of the most annoying with regard to food safety and pose serious health risk. Therefore, there is a requisite to propose suitable mitigation strategies to reduce the contamination of fungi and mycotoxins in agricultural commodities. In the present study, combinational inhibitory effect of Hedychium spicatum L. essential oil (HSEO) and radiation was established on growth rate, production of deoxynivalenol (DON) and zearalenone (ZEA) by Fusarium graminearum in maize grains. The HSEO was obtained from rhizomes by hydrodistillation technique and chemical composition was revealed by GC-MS analysis. A total of 48 compounds were identified and major compounds were 1,8-cineole (23.15\%), linalool (12.82\%), and $\beta$-pinene (10.06\%). The discrete treatments of HSEO and radiation were effective in reducing the fungal growth rate and mycotoxins content, and the complete reduction was noticed at $3.15 \mathrm{mg} / \mathrm{g}$ of HSEO and 6 kGy of radiation. Response surface methodology (RSM) was applied to evaluate the combinational inhibitory effect of HSEO and radiation treatments on fungal growth rate and mycotoxins content. A total of 13 experiments were designed with distinct doses of HSEO and radiation by central composite design (CCD) of Stat-Ease Design-Expert software. In combinational approach, complete reductions of fungal growth, DON, and ZEA content were noticed at $1.89 \mathrm{mg} / \mathrm{g}$ of HSEO and $4.12 \mathrm{kGy}$ of radiation treatments. The optimized design concluded that combinational treatments of HSEO and radiation were much more effective in reducing the fungal growth and mycotoxins content compared to their discrete treatments $(p<0.05)$. Responses of the design were assessed by second-order polynomial regression analysis and found that quadratic model was well fitted. The optimized design has larger $F$-value and adequate precision, smaller $p$-value, decent regression coefficients $\left(R^{2}\right)$ and found statistically significant $(\rho<0.05)$. In addition, correlation matrix, normal plot residuals, Box-Cox, and actual 
vs. predicted plots were endorsed that optimized design was accurate and appropriate. The proposed combinational decontamination technique could be highly applicable in agriculture and food industry to safeguard the food and feed products from fungi and mycotoxins.

Keywords: mycotoxins, Fusarium graminearum, Hedychium spicatum, deoxynivalenol, zearalenone, essential oil, $\gamma$-radiation, response surface methodology

\section{INTRODUCTION}

Mycotoxins are toxic secondary metabolites produced by filamentous fungi on agricultural products, which cause acute or chronic toxic effects in farm animals and humans called mycotoxicosis (Schirone et al., 2016; Du et al., 2017). The contamination of agricultural products with fungi occurs during pre-and post-harvesting stages due to inappropriate and unhygienic practices (Bernhoft et al., 2012). The Food and Agricultural Organization (FAO) of the United Nations estimate that $\sim 25 \%$ of agricultural products are contaminated with fungi and mycotoxins worldwide (Pitt and Hockings, 2009). The fungal infestation brings intolerable alterations in appearance, color, texture, flavor, and nutrition of food (Pitt and Hockings, 2009). Therefore, the incidence of fungi and mycotoxins contamination in agricultural products have become one of the foremost issues of farmers, food industry, and government concerning the food safety (Annunziata et al., 2017; Udomkun et al., 2017).

Among the mycotoxigenic fungi, Fusarium graminearum has received a wide attention because of its ability to produce a variety of mycotoxins, such as deoxynivalenol (DON), nivalenol (NIV), and zearalenone (ZEA) under diverse climate conditions (Pasquali et al., 2016). Several studies have addressed the toxic effects of DON and ZEA in in-vitro and in-vivo experiments and documented their genotoxicity, hepatotoxicity, neurotoxicity, immunotoxicity, nephrotoxicity, reproductive, and developmental toxicity, carcinogenicity, etc. (Zinedine et al., 2007; Venkataramana et al., 2014; Schumann et al., 2016; Kalagatur et al., 2017; Gonçalves et al., 2018; Muthulakshmi et al., 2018; Reddy et al., 2018). Moreover, International Agency for Research on Cancer (IARC) has studied the carcinogenic property of DON and ZEA in laboratory animals and classified as the group 3 carcinogens (IARC, 1999).

The DON and ZEA have been detected in wide range of agricultural commodities, such as barley, corn, corn silage, hay, oats, rice, sesame seed, sorghum, and wheat (CAST, 2003; Zinedine et al., 2007). Particularly, Fusarium head blight (FHB) in wheat and barley, and Gibberella ear rot in maize caused by F. graminearum is a devastating plant disease of temperate regions and results in yield loss and mycotoxins contamination (Wilson et al., 2018). Most lately, Xu et al. (2018) from North China Plain have detected as high as $95.7 \%$ of maize germ contamination with DON and measured average attendance of DON in processed products of maize germs as 163.7$1175.2 \mu \mathrm{g} / \mathrm{kg}$. In Hungary, Tima et al. (2018) have surveyed the occurrence of DON in maize, wheat and its by-products during the period 2008-2015 and noticed overall mean of $2,159 \pm 2,818 \mu \mathrm{g} / \mathrm{kg}$, which was annoyingly much higher than maximum allowed limit. Besides, Mallmann et al. (2017) have summarized the occurrence of DON and ZEA in barley and wheat grains of Southern Brazil during the middle of 20082015 and noticed $67 \%$ of DON and $41 \%$ of ZEA contamination. Similarly, Tralamazza et al. (2016) have observed 99\% of DON and $84 \%$ of ZEA contamination in wheat samples originated from Brazil. Also, Ji et al. (2014) have detected 74.4\% of wheat contaminated with DON in the FHB epidemic region of Jiangsu province, China. In our previous study (Mudili et al., 2014) $72-94 \mu \mathrm{g} / \mathrm{kg}$ of DON in freshly harvested maize grains from Andhra Pradesh, Karnataka, and Tamil Nadu states of Southern India was noticed. Furthermore, Mishra et al. (2013) have also measured the exposure and risk assessment of DON in the Indian individuals, and DON was identified in 30\% of cereal samples and in that $7 \%$ of samples were surpassed the FSSR (Food Safety and Standard Regulation, India) limit of $1 \mathrm{mg} / \mathrm{kg}$. In this context, F. graminearum and its toxins, DON, and ZEA have a great threat to the agricultural and food industry, especially in warm, and humid climate country like India (Ramana et al., 2011; Mishra et al., 2013; Divakara et al., 2014; Mudili et al., 2014; Aiyaz et al., 2016). In this scenario, there is a need to develop safe strategies to combat the problems of mycotoxigenic F. graminearum as well as DON and ZEA contamination in agricultural products.

Since last decade, agriculture and food industry have applied various decontamination practices to safeguard the agricultural products from fungi and mycotoxins (Zinedine et al., 2007; Kanapitsas et al., 2016; Kalagatur et al., 2018a,b). Unfortunately, some methods were undesirable, and only few of them were acceptable by WHO, FAO, EU, JECFA, and other regulatory agencies with some constraints. The application of synthetic fungicidal agents could drive the drug-resistant fungi, environmental pollution, health risk in animals and humans, and its use in food has been not passable and restricted worldwide (Kretschmer et al., 2009). Henceforth, there is a huge demand for bio-fungicides as an alternative to synthetic fungicidal agents (Akocak et al., 2015; George et al., 2016; Iram et al., 2016; Kumar et al., 2016; Sellamani et al., 2016; Kalagatur et al., 2017; Muniyandi et al., 2017). On the other hand, chemical decontamination methods bring unacceptable changes in the nutritional, sensory, and functional qualities of food and produce adverse toxic residues (Pitt and Hockings, 2009). The physical decontamination methods are most potent due to its spontaneous and strong effects. Particularly, radiation treatment is substantially efficient decontamination technique. The WHO and FDA of the United Nations have recognized that 
under well-established Good Manufacturing Practices (GMP) the application of $\gamma$-radiation in a low dose for disinfestations and enhancement of shelf life of agricultural commodities is nutritionally adequate and acceptable (Calado et al., 2014). Thus, a combination of biological and physical decontamination methods is likely to be a safe and much effective in controlling the fungal growth and mycotoxins content.

To the best of our knowledge, the combinational inhibitory action of essential oil and $\gamma$-radiation on the growth rate, production of DON and ZEA by $F$. graminearum has been not reported earlier. Therefore, the present study was aimed to establish the combinational inhibitory effect of Hedychium spicatum L. essential oil (HSEO) and radiation for the aforementioned purposes. The H. spicatum is a hardy and small perennial plant that belong to family Zingiberaceae and popularly known as "perfume ginger" or "spiked ginger lily" (Joshi et al., 2008). The HSEO is a rich source of diverse medicinal compounds, and it is widely used in herbal medicine to treat a variety of ailments, including nausea, stomachache, dysentery, local inflammations, asthma, bad breath, bronchitis, and rheumatic problems (Koul et al., 2005). The HSEO was obtained from rhizomes by hydrodistillation technique and its chemical profile was revealed by GC-MS analysis. The discrete inhibitory action of HSEO and radiation on the growth rate, production of DON, and ZEA by F. graminearum was evaluated in maize grains. Their combinational inhibitory action on aforementioned purposes was evaluated by response surface model adopting central composite design (CCD) and obtained model was validated experimentally.

\section{MATERIALS AND METHODS}

\section{Chemicals and Reagents}

Sabouraud dextrose agar (SDA), Sabouraud dextrose broth (SDB), and peptone were obtained from HiMedia (Mumbai, India). Certified standards of DON and ZEA were obtained from Sigma-Aldrich (Bengaluru, India). Immunoaffinity columns specific for DON and ZEA were procured from Vicam (Waters business, USA). The other chemicals used in the study were analytical grade and obtained from Merck Millipore (Bengaluru, India).

\section{Fungi Cultural Conditions}

Fusarium graminearum (MTCC 1893) capable for the synthesis of DON and ZEA was obtained from Microbial Type Culture Collection and Gene Bank (MTCC), India, and grown on SDA for 7 days at $28^{\circ} \mathrm{C}$. The fungal spores were collected by soft scrape in sterile peptone solution supplemented with $0.01 \%$ Tween 80 . The spore number was counted by hemocytometer and their number was set to $1 \times 10^{6}$ spores per $\mathrm{mL}$.

\section{Collection and Characterization of H. spicatum L. Essential Oil}

Plant Material Collection and Essential Oil Extraction

The rhizomes of $H$. spicatum were obtained from agricultural field, Ooty, Tamil Nadu, India. Plants were dried under shade for 2 weeks at $27 \pm 2^{\circ} \mathrm{C}$ and ground to a fine powder (voucher no:
PEO 37). The essential oil was extracted from $250 \mathrm{~g}$ of fine powder by hydrodistillation technique using Clevenger-type apparatus as per the procedure of European Pharmacopoeia (Council of Europe, 1997). The collected essential oil was dried over anhydrous sodium sulfate to get rid of moisture and safeguarded in an amber glass vial at $4^{\circ} \mathrm{C}$ for further analysis.

\section{Chemical Characterization of HSEO by GC-MS}

The chemical composition of HSEO was revealed by GCMS analysis using PerkinElmer Clarus 600 C (PerkinElmer, Inc., Waltham, USA) equipped with DB-5MS column $(30 \mathrm{~m} \times$ $0.25 \mathrm{~mm} ; 0.25 \mu \mathrm{m}$ film thickness) as per our previous reported methodology (Kalagatur et al., 2015). The chemical constituents of HSEO were identified by comparing their mass spectra (MS) with NIST/Wiley library and retention indices (RI) literature of Adams (2007). The quantification (\%) of chemical constituents was obtained from the GC peak areas devoid of correction factors.

\section{Radiation Treatment}

The radiation treatment was carried out in Gamma radiation chamber-5000 (Freeze Drying and Processing Technology Division, Defense Food Research Laboratory, Mysuru, India) and cobalt 60 was used as a source of $\gamma$-radiation with an effective dose frequency of $5.57 \mathrm{kGy}$ per $\mathrm{h}$ at $35^{\circ} \mathrm{C}$. The absorbed radiation dose was determined by a Ceric-cerous dosimeter that was fixed to the surface of the bottom and top of the test sample. The equivalence of radiation dose was stated as $\mathrm{D}_{\max } / \mathrm{D}_{\min }$ and it was 1.01 (Reddy et al., 2015).

\section{Assessment of Discrete and Combinational Inhibitory Effects of HSEO and Radiation Treatments on Growth Rate, Production of DON and ZEA by $F$. graminearum in Maize}

\section{Experimental Design}

The decisive aim of the present study was to evaluate the discrete and combinational inhibitory effects of HSEO and radiation treatments on the growth rate, production of DON and ZEA by F. graminearum in maize grains. The maize grains were obtained from the local agricultural market of Mysuru, Karnataka state, India, and $100 \mathrm{~g}$ was packed in plastic bags. The bags were autoclaved at $121^{\circ} \mathrm{C}$ for $20 \mathrm{~min}$ and grains were dried out in a hot air oven at $60^{\circ} \mathrm{C}$. The autoclaving process used for removal of background microbial flora could affect the texture of the grains and which could have an impact on the results presented in this study.

The fungal spore suspension of $10 \mu \mathrm{L}\left(1 \times 10^{6}\right.$ spores per $\mathrm{mL}$ ) was diluted to $1 \mathrm{~mL}$ with sterile peptone water solution and aseptically inoculated to the grain samples and mixed for $15 \mathrm{~min}$ at $140-160 \mathrm{rpm}$ in a rotary shaker (Aziz et al., 2007). Following, grain samples were separately exposed to different doses of HSEO and radiation treatments to evaluate their discrete inhibitory effect. The HSEO was directly applied to maize grains and thoroughly vortexed and mixed for $15 \mathrm{~min}$ at $140-160$ $\mathrm{rpm}$ in a rotary shaker as per methodology of Velluti et al. (2003). The combinational exposure of HSEO and radiation 
treatments with distinctive doses was accomplished by CCD of the response surface methodology (RSM) statistical program adopting State-Ease Design-Expert version 10.0.6.0 software application (Anderson and Whitcomb, 2016). In this study, grain samples initially treated with a distinctive concentration of HSEO were exposed to different doses of radiation treatment as per CCD. The grain samples were incubated for 14 days at water activity of 0.70 and temperature of $28^{\circ} \mathrm{C}$. The sample unexposed with HSEO and radiation treatments were referred as a control. Following the incubation period, the growth of fungi, quantification of DON, and ZEA were determined by colony forming units (CFU) and UHPLC, respectively.

The combinational inhibitory effect of HSEO and radiation (independent factors) on the reductions of CFU, DON, and ZEA content (response factors) was assessed by polynomial regression analysis of RSM. The lower and higher range of HSEO (0-3.15 $\mathrm{mg} / \mathrm{g})$ and radiation treatments (0-6 kGy) was fixed based on the dose required for complete inhibition of fungal growth and mycotoxins as per the study of their discrete exposure. The coded factors, name, units, range, levels, mean, and standard deviation of independent variables were shown in Supplementary Table 1. The order of experiments within the block was randomized and executed independently for six times. The regression analysis of attained responses i.e. $\log \mathrm{CFU}, \mathrm{DON}$, and ZEA were assessed by fitting with suitable models represented by the second-order polynomial equation.

$$
\mathrm{Y}=\beta_{0}+\sum_{i=1}^{n} \beta_{\mathrm{i}} \mathrm{x}_{\mathrm{i}}+\sum_{i=1}^{\mathrm{n}} \beta_{\mathrm{ii}} \mathrm{x}_{\mathrm{i}}^{2}+\sum_{\mathrm{i} \neq \mathrm{j}=1}^{n} \beta_{\mathrm{ii}} \mathrm{x}_{\mathrm{i}} x_{i j}
$$

where, "0" was the value of the fitted response at the center point of the design; i, ii, and ij were the linear, quadratic and crossproduct (interaction effect) regression terms, respectively and " $n$ " denoted the number of independent variables.

\section{Determination of Fungal Growth by Dilution Plating Technique}

The fungal growth in maize grains was determined as per methodology of Aziz et al. (2007) with minor modifications. Following the incubation period, $10 \mathrm{~g}$ of maize grains were collected from the plastic bags and suspended in $90 \mathrm{~mL}$ of sterile peptone water and mixed for $15 \mathrm{~min}$ at $140-160 \mathrm{rpm}$ in a rotary shaker. The decimal dilutions were prepared in sterile peptone water and spread plated on SDA plates and incubated at $28^{\circ} \mathrm{C}$ for 3 days. The fungal growth was determined in colony forming units (CFU) and results were expressed in log CFU/g.

\section{Quantification of DON and ZEA by UHPLC}

Following the incubation period, $25 \mathrm{~g}$ maize grains were collected from the test samples and ground to a fine powder under aseptic conditions and suspended in $250 \mathrm{~mL}$ solution of acetonitrile and water $(\mathrm{v} / \mathrm{v}, 6: 4)$. The blend was mixed for $15 \mathrm{~min}$ at 140 $160 \mathrm{rpm}$ and the supernatant was collected by centrifugation at $6000 \mathrm{rpm}$ for $5 \mathrm{~min}$. The supernatant was subjected to clean-up with immunoaffinity columns of DON and ZEA in according to the instructions of the manufacturer (Vicam, Waters business, USA). The quantification DON and ZEA were done as per our previous reported methodology (Mudili et al., 2014; Kalagatur et al., 2015) using UHPLC system (Nexera, Shimadzu, Japan). The quantification of DON and ZEA was deducted from their respective standard calibration curve and concentration was expressed in $\mu \mathrm{g} / \mathrm{g}$.

\section{Statistical Analysis}

The experiments were performed in six independent replicates. The statistical analysis was done according to the one-way ANOVA and significant differences were determined by Tukey's post hoc multiple comparison test and value of $p<0.05$ was considered significant. The statistical analysis and graphical illustrations were attained adopting the software program GraphPad Prism trial version 7 (GraphPad Software, Inc., USA). The statistical analysis for the optimization of RSM was done by CCD following the State-Ease Design-Expert trial version 10 software program (Stat-Ease, Inc., Minneapolis, USA). The responses of the polynomial regression at a significance level of $p<0.05$ were considered to design statistical model (Anderson and Whitcomb, 2016). The accuracy of the model was evaluated by measuring the coefficient of determination $\left(R^{2}\right)$ and lack of fit.

\section{RESULTS AND DISCUSSION \\ Chemical Composition of HSEO}

In the present study, the chemical composition of HSEO was revealed by GC-MS and a total of 48 compounds were identified constituting to $96.84 \%$ of total weight (Table 1). The major compounds were 1,8-cineole (23.15\%), linalool (12.82\%), $\beta$ pinene $(10.06 \%), \gamma$-terpinene $(8.16 \%)$, terpinolene $(5.04 \%), \alpha$ terpinene $(3.81 \%)$, and $\alpha$-terpineol (3.35\%). In our study, $\beta$ eudesmol, furanoid, $\beta$-himachalene, hedycaryol, eremoligenol, agarospirol, 8 -epi- $\beta$-bisabolol, and $\alpha$-cadinol were not detected in accordance with the previous reports of Joshi et al. (2008) and Sabulal et al. (2007). While, diverse compounds, such as terpinolene, $\alpha$-terpinyl acetate, $\gamma$-eudesmol, and $\gamma$-muurolene were identified in our study. The chemical compounds and their concentration of essential oil depend on the genetics of plant, part of the plant used, geographical origin, nutrients, harvesting time, and analytical method employed (Gobbo-Neto and Lopes, 2007). Therefore, in our study chemical compounds and their concentration values were varied in comparison to the previous reports.

\section{Inhibitory Effect of HSEO and Radiation Treatments on Growth Rate, Production of DON and ZEA by $F$. graminearum in Maize} Discrete Treatment of HSEO and Radiation

In the present study, discrete treatment of HSEO and radiation were effective in reducing the fungal growth (log CFU), production of DON and ZEA by F. graminearum in maize grains. A quantity of $5.79 \pm 0.33$ of $\log$ CFU/g, $6.24 \pm 0.37$ of DON $(\mu \mathrm{g} / \mathrm{g})$, and $8.67 \pm 0.45$ of ZEA $(\mu \mathrm{g} / \mathrm{g})$ were determined in the control sample. While, log CFU, DON, and ZEA content were reduced in test samples in a dose-dependent way with treatment of HSEO and radiation (Tables 2, 3). The fungal growth, DON, and ZEA content were not detected at $3.15 \mathrm{mg} / \mathrm{g}$ 
TABLE 1 | Chemical composition of Hedychium spicatum L. essential oil determined by GC-MS analysis.

\begin{tabular}{|c|c|c|c|c|}
\hline S. No & Compound & $\mathbf{R} \mathbf{I}^{*}$ & $\mathbf{R} \mathbf{I}^{\#}$ & Composition (\%) \\
\hline 1 & n-Nonane & 903 & 900 & 0.18 \\
\hline 2 & Tricyclene & 922 & 921 & 0.62 \\
\hline 3 & $\alpha$-Thujene & 925 & 924 & 0.05 \\
\hline 4 & $\alpha$-Pinene & 935 & 932 & 1.31 \\
\hline 5 & Camphene & 948 & 946 & 0.19 \\
\hline 6 & Sabinene & 970 & 969 & 0.34 \\
\hline 7 & $\beta$-Pinene & 976 & 974 & 10.06 \\
\hline 8 & $\beta$-Myrcene & 989 & 988 & 0.89 \\
\hline 9 & $\alpha$-Phellandrene & 1005 & 1002 & 2.27 \\
\hline 10 & $\alpha$-Terpinene & 1017 & 1014 & 3.81 \\
\hline 11 & p-Cymene & 1022 & 1020 & 0.22 \\
\hline 12 & Limonene & 1025 & 1024 & 2.29 \\
\hline 13 & 1,8-Cineole & 1028 & 1026 & 23.15 \\
\hline 14 & (E)- $\beta$-Ocimene & 1044 & 1044 & 1.53 \\
\hline 15 & $\gamma$-Terpinene & 1057 & 1054 & 8.16 \\
\hline 16 & Terpinolene & 1091 & 1086 & 5.04 \\
\hline 17 & Linalool & 1098 & 1095 & 12.82 \\
\hline 18 & n-Nonanal & 1104 & 1100 & 0.22 \\
\hline 19 & Camphor & 1144 & 1141 & 0.73 \\
\hline 20 & $\delta$-Terpineol & 1163 & 1162 & 2.89 \\
\hline 21 & Terpinen-4-ol & 1175 & 1174 & 2.06 \\
\hline 22 & $\alpha$-Terpineol & 1188 & 1186 & 3.35 \\
\hline 23 & trans-Carveol & 1218 & 1215 & 0.02 \\
\hline 24 & p-Cymen-7-ol & 1291 & 1289 & 0.85 \\
\hline 25 & $\delta$-Elemene & 1337 & 1335 & 0.02 \\
\hline 26 & $\alpha$-Terpinyl acetate & 1348 & 1346 & 2.91 \\
\hline 27 & $\beta$-Elemene & 1390 & 1389 & 0.87 \\
\hline 28 & Caryophyllene & 1418 & 1417 & 0.16 \\
\hline 29 & Santalene & 1450 & 1447 & 0.90 \\
\hline 30 & $\alpha$-Humulene & 1453 & 1452 & 0.34 \\
\hline 31 & $\gamma$-Muurolene & 1481 & 1478 & 0.71 \\
\hline 32 & Germacrene-D & 1486 & 1484 & 0.28 \\
\hline 33 & $\delta$-Selinene & 1495 & 1492 & 0.73 \\
\hline 34 & $\alpha$-Muurolene & 1502 & 1500 & 0.92 \\
\hline 35 & Germacrene A & 1510 & 1508 & 0.06 \\
\hline 36 & $\gamma$-Cadinene & 1513 & 1513 & 0.14 \\
\hline 37 & Cubebol & 1515 & 1514 & 0.19 \\
\hline 38 & $\delta$-Cadinene & 1527 & 1522 & 0.07 \\
\hline 39 & cis-Sesquisabinene hydrate & 1543 & 1542 & 0.53 \\
\hline 40 & Elemol & 1554 & 1548 & 0.04 \\
\hline 41 & (E)-Nerolidol & 1563 & 1561 & 0.39 \\
\hline 42 & Spathulenol & 1578 & 1577 & 0.81 \\
\hline 43 & Caryophyllene oxide & 1585 & 1582 & 0.60 \\
\hline 44 & 10-epi- $\gamma$-Eudesmol & 1625 & 1622 & 0.22 \\
\hline 45 & 1-epi-Cubenol & 1629 & 1627 & 0.37 \\
\hline 46 & $\gamma$-Eudesmol & 1634 & 1630 & 0.98 \\
\hline 47 & $\alpha$-Muurolol & 1649 & 1644 & 0.70 \\
\hline 48 & $\alpha$-Eudesmol & 1655 & 1652 & 0.85 \\
\hline Total & & & & $96.84 \%$ \\
\hline
\end{tabular}

*Actual retention indices of compounds on DB-5 column. "Retention indices of compounds on DB-5 column in accordance to literature of Adams (2007).
TABLE 2 | Discrete inhibitory effect of $H$. spicatum essential oil (HSEO) on growth rate (log CFU), production of deoxynivalenol (DON) and zearalenone (ZEA) by F. graminearum in maize grains.

\begin{tabular}{lcccc}
\hline S. No & $\begin{array}{c}\text { Dose of HSEO } \\
(\mathbf{m g} / \mathbf{g})\end{array}$ & Log CFU/g & DON $(\boldsymbol{\mu} \mathbf{g} / \mathbf{g})$ & ZEA $(\boldsymbol{\mu} \mathbf{g} / \mathbf{g})$ \\
\hline 1 & 0 (control) & $5.79 \pm 0.33^{\mathrm{a}}$ & $6.24 \pm 0.37^{\mathrm{a}}$ & $8.67 \pm 0.45^{\mathrm{a}}$ \\
2 & 0.5 & $5.38 \pm 0.28^{\mathrm{ab}}$ & $6.03 \pm 0.39^{\mathrm{ab}}$ & $7.95 \pm 0.36^{\mathrm{b}}$ \\
3 & 1 & $4.77 \pm 0.37^{\mathrm{c}}$ & $4.92 \pm 0.64^{\mathrm{c}}$ & $6.68 \pm 0.28^{\mathrm{c}}$ \\
4 & 1.5 & $3.36 \pm 0.29^{\mathrm{d}}$ & $3.68 \pm 0.45^{\mathrm{d}}$ & $4.60 \pm 0.23^{\mathrm{d}}$ \\
5 & 2 & $2.20 \pm 0.26^{\mathrm{e}}$ & $2.33 \pm 0.53^{\mathrm{e}}$ & $2.83 \pm 0.29^{\mathrm{e}}$ \\
6 & 2.5 & $1.04 \pm 0.17^{\mathrm{f}}$ & $1.19 \pm 0.21^{\mathrm{f}}$ & $1.58 \pm 0.20^{\mathrm{f}}$ \\
7 & 3 & $0.27 \pm 0.11^{\mathrm{g}}$ & $0.43 \pm 0.25^{\mathrm{g}}$ & $1.04 \pm 0.13^{\mathrm{g}}$ \\
8 & 3.15 & $0 \mathrm{gh}$ & $09^{\mathrm{h}}$ & $0^{\mathrm{h}}$
\end{tabular}

The data was processed by one-way ANOVA following Tukey's test and the columns with same alphabetic letters were not significant $(p<0.05)$.

TABLE 3 | Discrete inhibitory effect of radiation treatment on growth rate (log CFU), production of deoxynivalenol (DON) and zearalenone (ZEA) by F. graminearum in maize grains.

\begin{tabular}{lcccc}
\hline S. No & $\begin{array}{c}\text { Dose of radiation } \\
(\mathbf{k G y})\end{array}$ & Log CFU/g & DON $(\boldsymbol{\mu} \mathbf{g} / \mathbf{g})$ & ZEA $(\boldsymbol{\mu} \mathbf{g} / \mathbf{g})$ \\
\hline 1 & 0 (control) & $5.79 \pm 0.33^{\mathrm{a}}$ & $6.24 \pm 0.37^{\mathrm{a}}$ & $8.67 \pm 0.45^{\mathrm{a}}$ \\
2 & 1 & $5.26 \pm 0.30^{\mathrm{ab}}$ & $5.89 \pm 0.54^{\mathrm{ab}}$ & $7.64 \pm 0.49^{\mathrm{b}}$ \\
3 & 2 & $4.61 \pm 0.40^{\mathrm{c}}$ & $4.92 \pm 0.71^{\mathrm{bc}}$ & $6.42 \pm 0.35^{\mathrm{c}}$ \\
4 & 3 & $3.66 \pm 0.38^{\mathrm{d}}$ & $3.73 \pm 0.89^{\mathrm{d}}$ & $4.87 \pm 0.41^{\mathrm{d}}$ \\
5 & 4 & $2.39 \pm 0.37^{\mathrm{e}}$ & $2.66 \pm 0.79^{\mathrm{de}}$ & $3.70 \pm 0.35^{\mathrm{e}}$ \\
6 & 5 & $1.41 \pm 0.46^{\mathrm{f}}$ & $1.58 \pm 0.75^{\mathrm{ef}}$ & $1.84 \pm 0.38^{f}$ \\
7 & 6 & $0^{\mathrm{g}}$ & $0^{\mathrm{g}}$ & $00^{\mathrm{g}}$ \\
\hline
\end{tabular}

The data was processed by one-way ANOVA following Tukey's test and the columns with same alphabetic letters were not significant $(p<0.05)$.

of HSEO and $6 \mathrm{kGy}$ of radiation. The linear regression curves for reductions of $\log \mathrm{CFU}, \mathrm{DON}$, and ZEA content were constructed against different doses of HSEO and radiation (Figures 1, 2). The obtained regression models exhibited the goodness of fit $\left(R^{2}\right)$ close to 1 and found statistically significant $(p<0.05$; Tables 4,5). The regression models confirmed that reductions of $\log$ CFU, DON, and ZEA content by HSEO and radiation were dose-dependent.

Best of our knowledge, till the date, the fungicidal activity of HSEO on F. graminearum was not reported, and this is the first report. On the other hand, Pawar and Thaker (2006) has determined the antifungal activity of HSEO on Aspergillus niger by a zone of inhibition assay as $8 \mathrm{~mm}$. The growth inhibitory activity of radiation treatment on $F$. graminearum was less investigated. In support of our study, very few reports are available on the application of radiation treatment in the management of $F$. graminearum in food and feed matrices. Aziz et al. (2007) have reported the complete inhibition of Fusarium spp. growth at $4 \mathrm{kGy}$ in barley and $6 \mathrm{kGy}$ in wheat and maize grains. On the other hand, Ferreira-Castro et al. (2007) and Lima et al. (2011) have documented that high dose of $10 \mathrm{kGy}$ radiation treatment was required for complete reduction of Fusarium spp. in maize and cowpea bean grains, respectively. The 

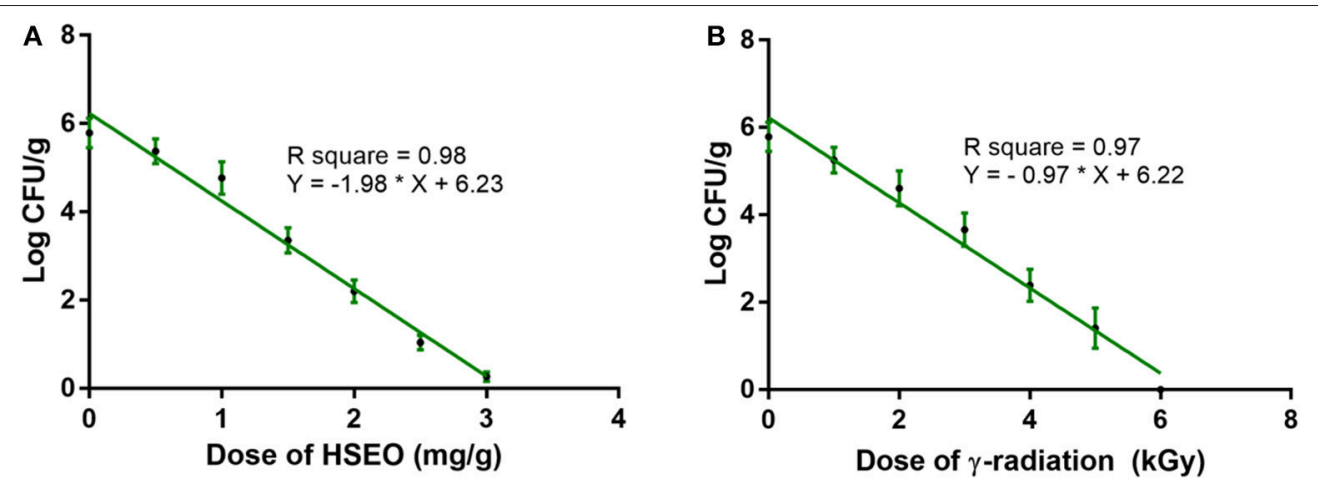

FIGURE 1 | Linear regression curve for growth inhibitory activity of different doses of (A) H. spicatum L. essential oil (HSEO) and (B) radiation treatments on F. graminearum in maize. The log CFU/g was declined with the dose of HSEO and radiation. The data was processed by one-way ANOVA following Tukey's test and value of $p<0.05$ was considered significant.
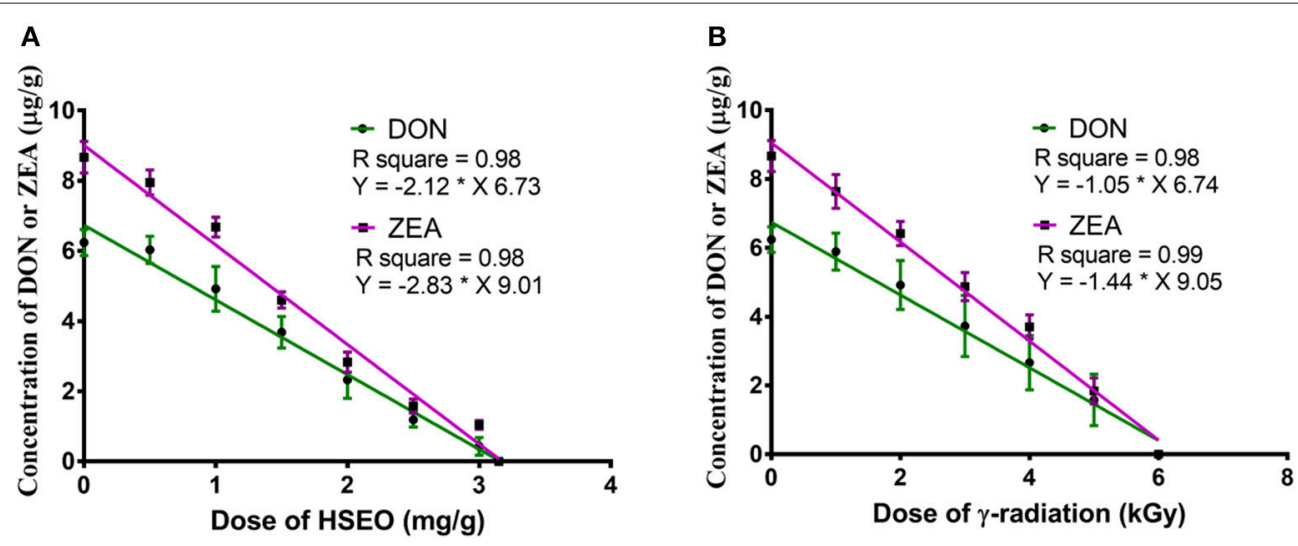

FIGURE 2 | Linear regression curve for dose-dependent effect of (A) H. spicatum L. essential oil (HSEO) and (B) radiation treatments on the reductions of deoxynivalenol (DON) and zearalenone (ZEA) content by F. graminearum in maize. The data was analyzed by one-way ANOVA following Tukey's test and value of $p<0.05$ was considered significant.

radiation dose required for reduction of fungal growth depends on certain factors, such as the type of species, population number, intensity of pigmentation, water content, genetics, and induction of protective enzymes, which play a major role in the regaining of the damage induced by radiation (Jeong et al., 2015). In the present study, the background microbial flora of maize grains was removed by autoclave sterilization and which could affect the texture of the grains and have an impact on the results. Therefore, the differences in the radiation dose required for complete reduction of fungal growth were noticed in present and previous studies.

\section{Combinational Treatment of HSEO and Radiation}

Radiation process is measured as an ideal and beneficial decontamination technique at a low dose. High radiation dose produces intolerable features and toxic substances in food, such as structural and chemical changes, nutritional and sensory loss, undesirable odor and flavor, and rancidity (Calado et al., 2014). Therefore, minimally radiation processed foods are highly preferred and acceptable by consumer and regulatory bodies. In this context, food industry and food technologists have made many efforts through last decade to reduce the efficient radiation dosage rate and augment the decontamination efficiency of radiation. Currently, combining radiation with other decontamination agents, such as essential oils, chemical preservatives, and modified atmospheres is an effective and innovative way to improve the decontamination efficiency of radiation (Ghosh et al., 2017; Sirocchi et al., 2017; Wilson et al., 2017). The combinational approach reduces the possible means radiation dose required for decontamination of microbial flora and could promote food safety at low radiation dosage.

The combinational inhibitory effect of HSEO and radiation treatments on the fungal growth $(\log \mathrm{CFU})$, production of DON and ZEA by $F$. graminearum in maize grains were executed following the CCD of RSM statistical program (Wu et al., 2017). The RSM is a collection of statistical and mathematical techniques, and one of the widely used applications in the design, development, and invention of new process or products, and improvement of an existing process or product designs in food science and technology. The RSM requires only a minimal 
TABLE 4 | Linear regression curve for discrete inhibitory effect of $H$. spicatum essential oil (HSEO) on growth rate (log CFU), production of deoxynivalenol (DON) and zearalenone (ZEA) by F. graminearum in maize grains.

$\log \mathrm{CFU} / \mathrm{g}$

$-1.98 \pm 0.12$

$6.23 \pm 0.22$

3.14

$-0.50$

\section{1/slope}

95\% CONFIDENCE INTERVALS

\section{Slope}

Y-intercept

X-intercept

\section{GOODNESS OF FIT}

$\begin{array}{lccc}\text { R square } & 0.98 & 0.98 & 0.98 \\ \text { Sy.X } & 0.33 & 0.30 & 0.44 \\ \text { IS SLOPE SIGNIFICANTLY NON-ZERO? } & & & 446.8 \\ F & 248.3 & 1,6 & 379.8 \\ \text { DFn, DFd } & 1,6 & <0.005 & 1,6 \\ P \text {-value } & <0.005 & \text { Significant } & <.005 \\ \text { Deviation from zero? } & \text { Significant } & Y=-2.12^{*} X+6.73 & Y=-2.83^{*} X+9.01\end{array}$

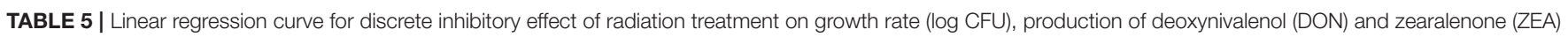
by $F$. graminearum in maize grains.

\begin{tabular}{|c|c|c|c|}
\hline & Log CFU/g & DON $(\mu \mathrm{g} / \mathrm{g})$ & ZEA $(\mu \mathrm{g} / \mathrm{g})$ \\
\hline \multicolumn{4}{|c|}{ BEST-FIT VALUES \pm SE } \\
\hline Slope & $-0.97 \pm 0.06$ & $-1.05 \pm 0.06$ & $-1.44 \pm 0.06$ \\
\hline Y-intercept & $6.22 \pm 0.23$ & $6.74 \pm 0.23$ & $9.05 \pm 0.2$ \\
\hline X-intercept & 6.38 & 6.38 & 6.28 \\
\hline 1/slope & -1.02 & -0.94 & -0.69 \\
\hline \multicolumn{4}{|c|}{ 95\% CONFIDENCE INTERVALS } \\
\hline Y-intercept & 5.63 to 6.82 & 6.13 to 7.35 & 8.46 to 9.64 \\
\hline X-intercept & 5.80 to 7.17 & 5.82 to 7.10 & 5.88 to 6.77 \\
\hline \multicolumn{4}{|l|}{ GOODNESS OF FIT } \\
\hline R square & 0.97 & 0.98 & 0.99 \\
\hline Sy.x & 0.34 & 0.34 & 0.33 \\
\hline$P$-value & $<0.005$ & $<0.005$ & $<0.005$ \\
\hline Deviation from zero? & Significant & Significant & Significant \\
\hline Equation & $Y=-0.97^{\star} X+6.22$ & $Y=-1.05^{\star} X+6.74$ & $Y=-1.44^{*} X+9.05$ \\
\hline
\end{tabular}

number of experiments between input variables that potentially influence performance measures or quality characteristics of the product or process and allow to identify breakthrough productive information by means of reducing cost, errors, and disturbance. The relations between the input factors and responses were hypothesized or assessed by choosing a model (Whitcomb and Anderson, 2004).
The actual or obtained response of 13 CCD experiments of the present study was provided in Table 6 . The data was analyzed by second-order polynomial regression analysis employing the software Design Expert (version 10.0.6) to optimize the response surface models.

The correlation matrix of regression coefficients of independent factors was correlated with one another on a 
TABLE 6 | Central composite design (CCD) for combinational inhibitory action of $H$. spicatum essential oil (HSEO) and radiation treatments (independent factors) on the reductions of log CFU, DON, and ZEA (responses).

\begin{tabular}{|c|c|c|c|c|c|}
\hline Run order & \multicolumn{2}{|c|}{ Independent factors } & \multicolumn{3}{|c|}{ Actual responses } \\
\hline 1 & $0.25(-1)$ & $5.52(1)$ & $1.02 \pm 0.33$ & $1.19 \pm 0.23$ & $1.56 \pm 0.41$ \\
\hline 2 & $1.57(0)$ & $3(0)$ & $1.07 \pm 0.18$ & $1.26 \pm 0.47$ & $1.71 \pm 0.67$ \\
\hline 3 & $0.25(-1)$ & $0.47(-1)$ & $5.42 \pm 0.37$ & $5.97 \pm 0.54$ & $7.68 \pm 0.84$ \\
\hline 4 & $1.57(0)$ & $3(0)$ & $0.84 \pm 0.35$ & $1.14 \pm 0.34$ & $1.32 \pm 0.28$ \\
\hline 7 & $1.57(0)$ & $3(0)$ & $0.81 \pm 0.20$ & $1.02 \pm 0.29$ & $1.64 \pm 0.40$ \\
\hline 8 & $1.57(0)$ & $6(2)$ & 0.00 & 0.00 & 0.00 \\
\hline 9 & $2.89(1)$ & $0.47(-1)$ & $0.84 \pm 0.31$ & $1.12 \pm 0.20$ & $1.47 \pm 0.25$ \\
\hline 10 & $0(-2)$ & $3(0)$ & $3.79 \pm 0.58$ & $4.12 \pm 0.42$ & $5.38 \pm 0.45$ \\
\hline 11 & $2.89(1)$ & $5.52(1)$ & 0.00 & 0.00 & 0.00 \\
\hline
\end{tabular}
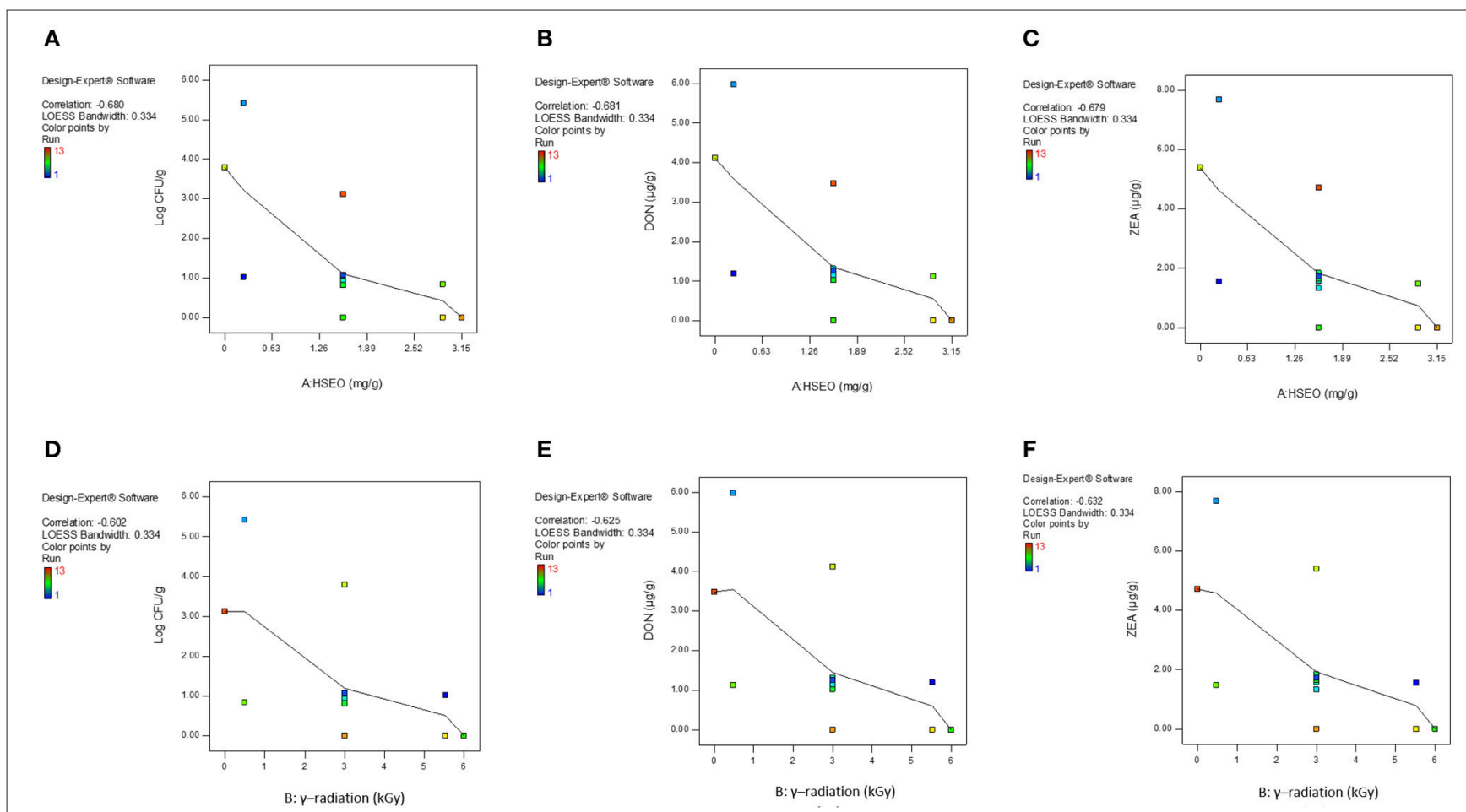

FIGURE 3 | Correlation matrix plots of HSEO (A-C) and radiation treatments (D-F) to accomplish their suitability for responses: log CFU, DON, and ZEA.

scale of perfect negative correlation $(-1)$ to perfect positive correlation $(+1)$ as per Pearson's correlation coefficients to conclude their appropriateness. The perfect negative correlated matrix was appropriate and agrees to the individual effect of independent factors on responses (Anderson and Whitcomb, 2016). In the present study, a perfect negative correlation matrix was observed for both independent factors (Figure 3). A perfect negative correlation matrix of -0.680 and -0.602 (log CFU), -0.681 and $-0.625(\mathrm{DON})$, and -0.679 and -0.632 (ZEA) were observed for HSEO and radiation treatments, respectively. It indicated that independent factors were independently effective in reducing the log CFU, DON, and ZEA. These results were in accordance with the assessment of the discrete inhibitory effect of HSEO and radiation treatments on the reductions of $\log$ CFU, DON, and ZEA content (Figures 1, 2). Therefore, the combinational assessment of HSEO and radiation treatments for the aforementioned purposes were well appropriate and could reveal newer insights. Consequently, combinational treatments 
of HSEO and radiation were highly effective in reducing the log CFU, DON, and ZEA content in maize grains. The complete reductions of fungal growth, DON, and ZEA content were noticed at combination of $1.89 \mathrm{mg} / \mathrm{g}$ of HSEO and $4.12 \mathrm{kGy}$ of radiation treatments (Table 11). The dose of HSEO (1.89 $\mathrm{mg} / \mathrm{g}$ ) and radiation $(4.12 \mathrm{kGy})$ required for complete reductions of fungal growth, DON, and ZEA content were much less in combinational treatment compared to discrete treatments of HSEO $(3.15 \mathrm{mg} / \mathrm{g})$ and radiation $(6 \mathrm{kGy})$.

The obtained CCD results of the RSM study concluded that quadratic model was well appropriate for all the responses (log CFU, DON, and ZEA). The coefficient of independent variables in terms actual factors for second-order polynomial equation designed for the responses attained as below:

$$
\begin{aligned}
\log \mathrm{CFU} / \mathrm{g}= & +6.87-2.98 * \mathrm{HSEO}-1.27 * \text { radiation } \\
& +0.26 * \mathrm{HSEO} * \text { radiation }+0.34 * \mathrm{HSEO}^{2} \\
& +0.05 * \text { radiation }^{2} \\
\operatorname{DON}(\mu \mathrm{g} / \mathrm{g})= & +7.42-3.03 * \mathrm{HSEO}-1.32 * \text { radiation } \\
& +0.27 * \mathrm{HSEO} * \text { radiation }+0.31 * \mathrm{HSEO}^{2} \\
& +0.05 * \text { radiation }^{2} \\
\mathrm{ZEA}(\mu \mathrm{g} / \mathrm{g})= & +9.61-3.81 * \mathrm{HSEO}-1.72 * \text { radiation }^{2} \\
& +0.34 * \mathrm{HSEO}^{2} \text { radiation }+0.38 * \mathrm{HSEO}^{2} \\
& +0.06 * \text { radiation }
\end{aligned}
$$

The significance of the second-order polynomial model was evaluated by analysis of variance (ANOVA) and coefficient of determination $\left(R^{2}\right)$. The ANOVA results for the fitted quadratic polynomial models of log CFU, DON, and ZEA were presented in Tables 7, 8, 9, respectively. For any of the terms in the model, a greater $F$-value and smaller $p$-value would indicate a more significant effect on the respective response variables (Atkinson and Donev, 1992). The present model has larger Fvalue of $251.61(\log \mathrm{CFU}), 335.88(\mathrm{DON})$, and 229.45 (ZEA) and the associated $p$-value $<0.0001$ and implied that the optimized models were very significant. Furthermore, $F$-value and $p$-value of the lack of fit were 4.44 and 0.0918 for $\log$ CFU, 2.37 and 0.2120 for DON, 2.24 and 0.2255 for ZEA, respectively (Table 10). Which indicated that lack of fit was not significant and $9.18 \%, 21.20 \%$, and $22.55 \%$ chance could occur due to noise in log CFU, DON, and ZEA, respectively. The goodness of fit of the models was judged by estimating the coefficient of determination $\left(R^{2}\right)$. The value of $R^{2}$ for $\log$ CFU, DON, and ZEA were observed as $0.9945,0.9958$, and 0.9939 , respectively. Which implies that $99.45 \%, 99.58 \%$, and $99.39 \%$ of the variations could be explained by the fitted models of log CFU, DON, and ZEA, respectively. For a good statistical model, the predicted Rsquared value should be close to adjusted R-squared value and the obtained differences in all the responses of the present study

\begin{tabular}{|c|c|c|c|c|c|}
\hline Source & $\begin{array}{l}\text { Sum of } \\
\text { squares }\end{array}$ & $\begin{array}{c}\text { Degree of } \\
\text { freedom (df) }\end{array}$ & $\begin{array}{l}\text { Mean } \\
\text { square }\end{array}$ & $F$-value & $\begin{array}{c}p \text {-value } \\
\text { Prob }>F\end{array}$ \\
\hline Model & 32.18 & 5 & 6.44 & 251.61 & $\begin{array}{l}0.0918 \\
\text { significant }\end{array}$ \\
\hline A-HSEO & 14.96 & 1 & 14.96 & 584.89 & $<0.0001$ \\
\hline B-Radiation & 11.73 & 1 & 11.73 & 458.67 & $<0.0001$ \\
\hline$A B$ & 3.17 & 1 & 3.17 & 123.87 & $<0.0001$ \\
\hline$A^{2}$ & 1.56 & 1 & 1.56 & 60.84 & 0.0001 \\
\hline$B^{2}$ & 0.57 & 1 & 0.57 & 22.11 & 0.0022 \\
\hline Residual & 0.18 & 7 & 0.026 & & \\
\hline Lack of fit & 0.14 & 3 & 0.046 & 4.44 & $\begin{array}{c}0.0918 \\
\text { not significant }\end{array}$ \\
\hline Pure error & 0.041 & 4 & 0.010 & & \\
\hline Cor total & 32.36 & 12 & & & \\
\hline
\end{tabular}
were appropriate (Table 10). Also, adequate precision should be $>4.0$ is desirable for the significant model and adequate precision

\begin{tabular}{|c|c|c|c|c|c|}
\hline Source & $\begin{array}{l}\text { Sum of } \\
\text { squares }\end{array}$ & $\begin{array}{c}\text { Degree of } \\
\text { freedom (df) }\end{array}$ & $\begin{array}{l}\text { Mean } \\
\text { square }\end{array}$ & $F$-value & $\begin{array}{c}p \text {-value } \\
\text { Prob }>F\end{array}$ \\
\hline Model & 37.67 & 5 & 7.53 & 335.88 & $\begin{array}{l}<0.0001 \\
\text { significant }\end{array}$ \\
\hline A-HSEO & 17.53 & 1 & 17.53 & 781.33 & $<0.0001$ \\
\hline B-Radiation & 14.76 & 1 & 14.76 & 657.91 & $<0.0001$ \\
\hline$A B$ & 3.35 & 1 & 3.35 & 149.30 & $<0.0001$ \\
\hline$A^{2}$ & 1.38 & 1 & 1.38 & 61.36 & 0.0001 \\
\hline$B^{2}$ & 0.49 & 1 & 0.49 & 21.84 & 0.0023 \\
\hline Residual & 0.16 & 7 & 0.022 & & \\
\hline Lack of fit & 0.10 & 3 & 0.033 & 2.37 & $\begin{array}{c}0.2120 \\
\text { not significant }\end{array}$ \\
\hline Pure error & 0.057 & 4 & 0.014 & & \\
\hline Cor total & 37.83 & 12 & & & \\
\hline
\end{tabular}
of 52.343 (log CFU), 60.519 (DON), and 50.190 (ZEA) in the
TABLE 7 | ANOVA for log CFU/g response surface quadratic model.

\begin{tabular}{|c|c|c|c|c|c|}
\hline Source & $\begin{array}{l}\text { Sum of } \\
\text { squares }\end{array}$ & $\begin{array}{l}\text { Degree of } \\
\text { freedom (df) }\end{array}$ & $\begin{array}{l}\text { Mean } \\
\text { square }\end{array}$ & $F$-value & $\begin{array}{l}p \text {-value } \\
\text { Prob }>F\end{array}$ \\
\hline Model & 63.36 & 5 & 12.67 & 229.45 & $\begin{array}{l}<0.0001 \\
\text { significant }\end{array}$ \\
\hline A-HSEO & 29.40 & 1 & 29.40 & 532.25 & $<0.0001$ \\
\hline B-Radiation & 25.48 & 1 & 25.48 & 461.39 & $<0.0001$ \\
\hline$A B$ & 5.41 & 1 & 5.41 & 97.88 & $<0.0001$ \\
\hline$A^{2}$ & 1.98 & 1 & 1.98 & 35.84 & 0.0005 \\
\hline$B^{2}$ & 0.83 & 1 & 0.83 & 15.04 & 0.0061 \\
\hline Residual & 0.39 & 7 & 0.055 & & \\
\hline Lack of fit & 0.24 & 3 & 0.081 & 2.24 & $\begin{array}{c}0.2255 \\
\text { not significant }\end{array}$ \\
\hline Pure error & 0.14 & 4 & 0.036 & & \\
\hline Cor total & 63.75 & 12 & & & \\
\hline
\end{tabular}

TABLE 8 | ANOVA for DON $(\mu \mathrm{g} / \mathrm{g})$ response surface quadratic model.

TABLE 9 | ANOVA for ZEA $(\mu \mathrm{g} / \mathrm{g})$ response surface quadratic model.

present study indicates an adequate signal and the obtained models were well appropriate to navigate the design space (Table 10). 
TABLE 10 | Sequential model and regression coefficients of optimized designs.

\begin{tabular}{lccc}
\hline Term model & \multicolumn{3}{c}{ Responses } \\
\cline { 2 - 4 } & Log CFU/g & DON $(\boldsymbol{\mu} \mathbf{g} / \mathbf{g})$ & ZEA $(\boldsymbol{\mu} \mathbf{g} / \mathbf{g})$ \\
\hline F-Value & 251.61 & 335.88 & 229.45 \\
$P>F$ & $<0.0001$ & $<0.0001$ & $<0.0001$ \\
Mean & 1.44 & 1.68 & 2.22 \\
Standard deviation & 0.16 & 0.15 & 0.24 \\
C V \% & 11.08 & 8.90 & 10.58 \\
R squared & 0.9945 & 0.9958 & 0.9939 \\
Adjusted R squared & 0.9905 & 0.9929 & 0.9896 \\
Predicted R squared & 0.9664 & 0.9771 & 0.9673 \\
Adequate precision & 52.343 & 60.519 & 50.190 \\
Model & Quadratic & Quadratic & Quadratic
\end{tabular}

The diagnostic and correlation plots were judged to endorse the obtained significance of ANOVA. The normal plot residuals of normal \% probability vs. externally studentized residuals were constructed to illustrate the accuracy of optimized design (Figure 4). The distribution of externally studentized residuals was satisfactorily followed the normal distribution. Which indicated that residuals plots follow linear behavior and the predicted model is accurate (Myers et al., 2016). A Box-Cox plot for power transforms of responses were considered to determine the most appropriate power law transformation to fit the responses. The best recommended transform $(\lambda)$ of $0.80,0.94$, and 0.91 were observed for $\log \mathrm{CFU}, \mathrm{DON}$, and ZEA, respectively (Figure 5). The obtained $\lambda$ values were close to the current value of 1 for none and which indicates that responses were well fitted by the optimized design (Box and Cox, 1964). The optimized designs were assessed to examine the correlation between the actual and predicted responses (Figure 6). The obtained data points were close to the straight line and presented a good correlation coefficient $\left(R^{2}\right)$. The correlation curves suggested a high degree correlation of 0.9945 , 0.9958 , and 0.9939 between the actual and predicted values of the $\log$ CFU, DON, and ZEA, respectively and concluded that the fundamental assumptions of the analysis were well appropriate. The fitted polynomial equation was expressed as $3 \mathrm{D}$ surface plots to illustrate the interactive effects of the independent variables on the responses and to deduce optimum conditions (Figure 7). In conclusion, appropriateness of the optimized model for predicting the optimum responses was verified with suggested optimum conditions. The obtained actual values of suggested experiments were found in agreement with the predicted values (Table 11). The complete reductions of fungal growth (log $\mathrm{CFU}$ ), DON, and ZEA content were noticed in maize grains at combinational treatment of $1.89 \mathrm{mg} / \mathrm{g}$ of HSEO and $4.12 \mathrm{kGy}$ of radiation. These results suggested that the designed quadratic models for reductions of log CFU, DON, and ZEA content in maize grains were statistically significant and could adequately represent the real interdependence of factors chosen (HSEO and radiation).

The present study concluded that combinational exposure of HSEO and radiation on the reductions of fungal growth,
DON, and ZEA content by $F$. graminearum in maize grains was highly efficient compared to their discrete exposure. In combinational approach, radiation dose required for complete reductions of fungi and mycotoxins were reduced from $6 \mathrm{kGy}$ (discrete treatment) to $4.12 \mathrm{kGy}$. Which indicated that radiation treatment with the combination of HSEO was highly efficient and minimally radiation processed compared to unaccompanied treatment of radiation. However, structural, chemical and nutritional changes of maize grains were not determined in the present study. In support of our study, earlier reports demonstrated that essential oils with a combination of modified atmosphere packaging, mild heat treatment, and radiation were highly effective and safe in maintaining the microbiological safety of the food (Hossain et al., 2014). Several studies noticed that antifungal activity of essential oils is reliant on chemical constituents and their synergistic action (Hyldgaard et al., 2012; da Cruz Cabral et al., 2013). In our study, varieties of chemical compounds were noticed in HSEO (Table 1) and the attributed antifungal activity of HSEO against $F$. graminearum could be due to individual and combination of action of 1,8-cineole, linalool, $\beta$-pinene, limonene, germacrene-D, $\gamma$-terpinene, terpinolene, $\alpha$ terpinene, and $\alpha$-terpineol (Velluti et al., 2003; Van Vuuren and Viljoen, 2007; Deba et al., 2008; Chee et al., 2009; Vilela et al., 2009; Gao et al., 2016). These compounds could alter the integrity of cell membrane and disturb the membrane fluidity, osmotic balance, enzymatic functions, and leak cytoplasmic contents of the cell. These cascade of events stops the ATP synthesis, growth and proliferation of fungi, and activates the caspase-mediated apoptotic death by releasing the mitochondrial cytochrome $\mathrm{c}$ and death receptors (Ramsdale, 2008; Usta et al., 2009; Tian et al., 2012; Chen et al., 2014). In case of radiation treatment, radiolysis of cellular water of organisms produces positive-charged water radicals $\left(\mathrm{H}_{2} \mathrm{O}^{+}\right)$and negative-charged free electrons $\left(\mathrm{e}^{-}\right)$, and a series of cross-combination and recombination reactions generate highly reactive molecules (de Campos et al., 2004; Le Caër, 2011). These molecules attack and cleave hydrogen from sugar and bases of nuclear material, and destruct the other cellular components, i.e., protein and lipids and even damage the integrity of cellular membranes. This process inhibits spore germination and biomass production and promotes the death of fungi (Calado et al., 2014).

Henceforth, combined treatments of HSEO and radiation presented a superior antifungal efficiency on F. graminearum than the discrete treatment of HSEO or radiation alone. Moreover, many reports showed that the combinational treatment of essential oils with radiation up to a dose of 10 $\mathrm{kGy}$ do not produce any significant changes in the quality and quantity of essential oils and not produce any toxic residues (Chatterjee et al., 2000; Haddad et al., 2007). Consequently, functional features of essential oils do not effect on exposure to radiation and acceptable by Institute of Food Science \& Technology (IFST), WHO, FAO, International Atomic Energy Agency (IAEA), and consumer (Lacroix and Ouattara, 2000; IAEA, 2001; Maherani et al., 2016). Henceforth, the proposed novel combinational exposure of HSEO and radiation could be highly acceptable and efficient for reductions of fungal growth and mycotoxins in food and feed matrices and thereby support in 

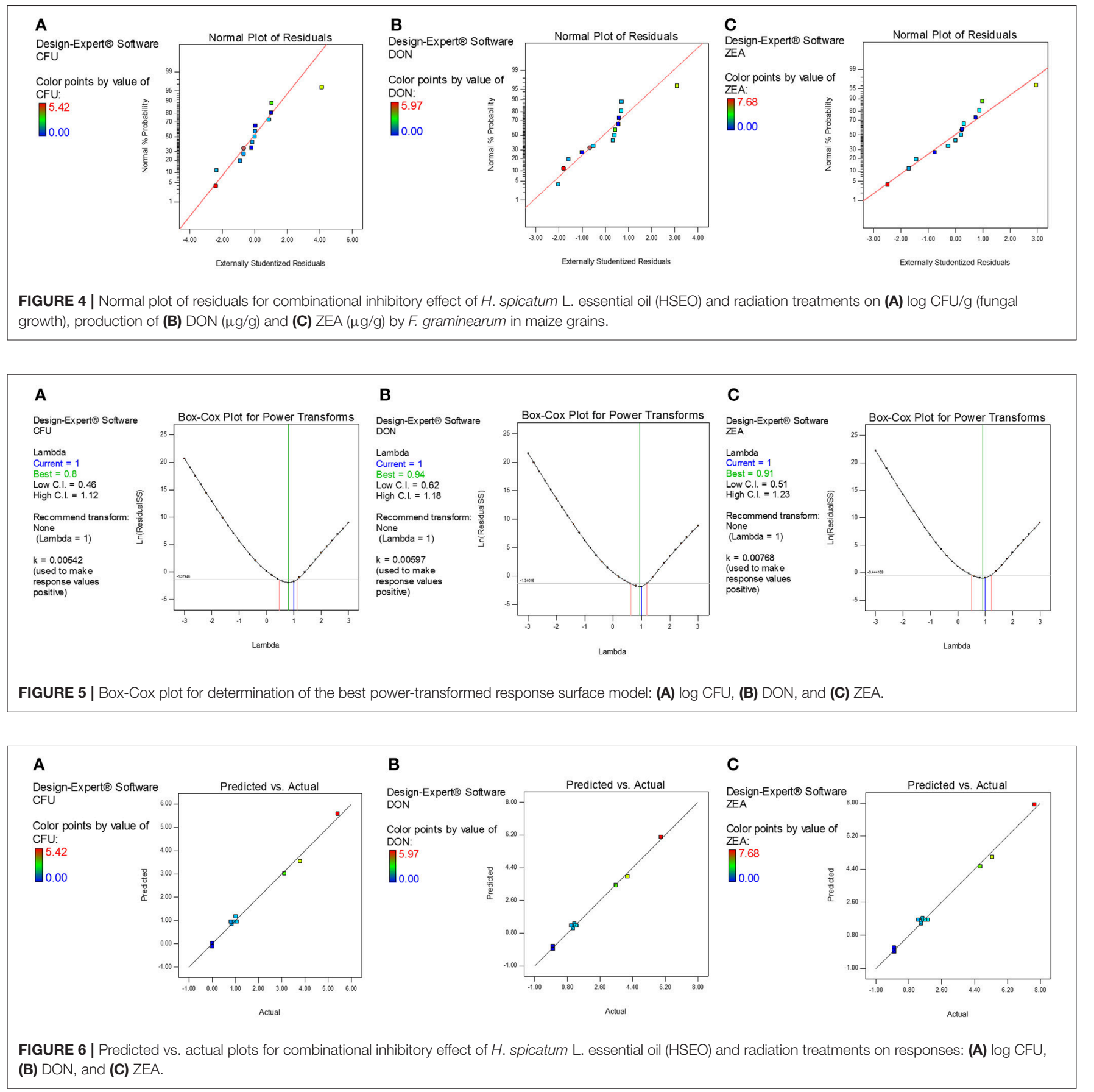

obtaining the highly microbiological safe food products. Though, a greater understanding of the combinational antifungal activity of essential oils and radiation is required at the cellular and molecular level to exploit underlying the molecular death machinery.

\section{CONCLUSION}

In the present study, the discrete and combinational inhibitory effects of HSEO and radiation treatments on growth, production of DON and ZEA by $F$. graminearum in maize grains were assessed under laboratory set-ups. The GC-MS analysis of HSEO revealed the presence of 48 compounds constituting to $96.84 \%$ of total weight and major compounds were 1,8 cineole, linalool, and $\beta$-pinene. The simple linear regression analysis showed that HSEO and radiation treatments were discretely inhibited the fungal growth, DON, and ZEA content in maize grains by the dose-dependent way, and complete inhibition were noticed at $3.15 \mathrm{mg} / \mathrm{g}$ of HSEO and $6 \mathrm{kGy}$ of radiation. The combinational inhibitory action of HSEO and 


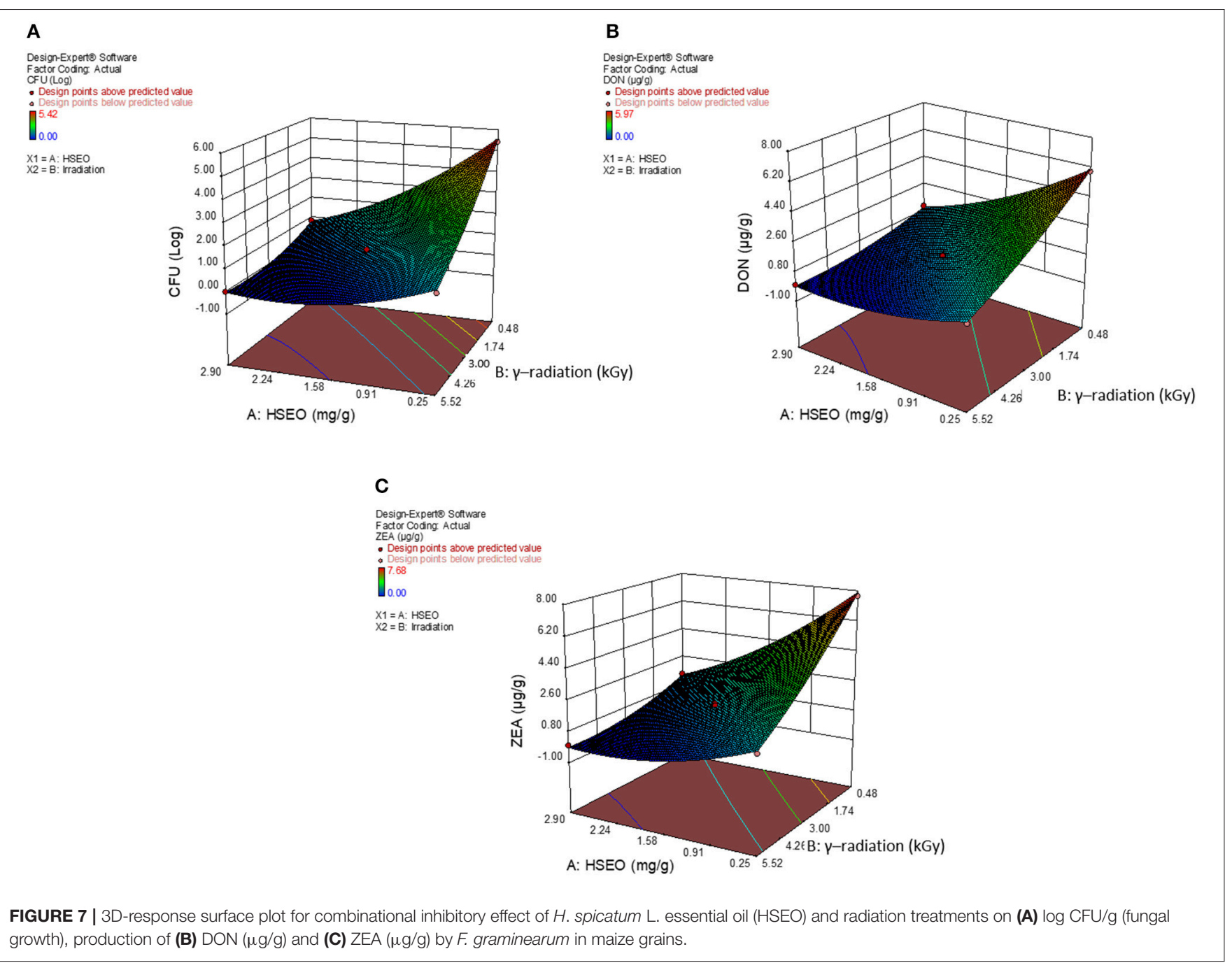

TABLE 11 | Assessment of proposed predicted values of design with actual values of experiment to maximize the inhibition of growth rate, DON, and ZEA by F. graminearum in maize grains.

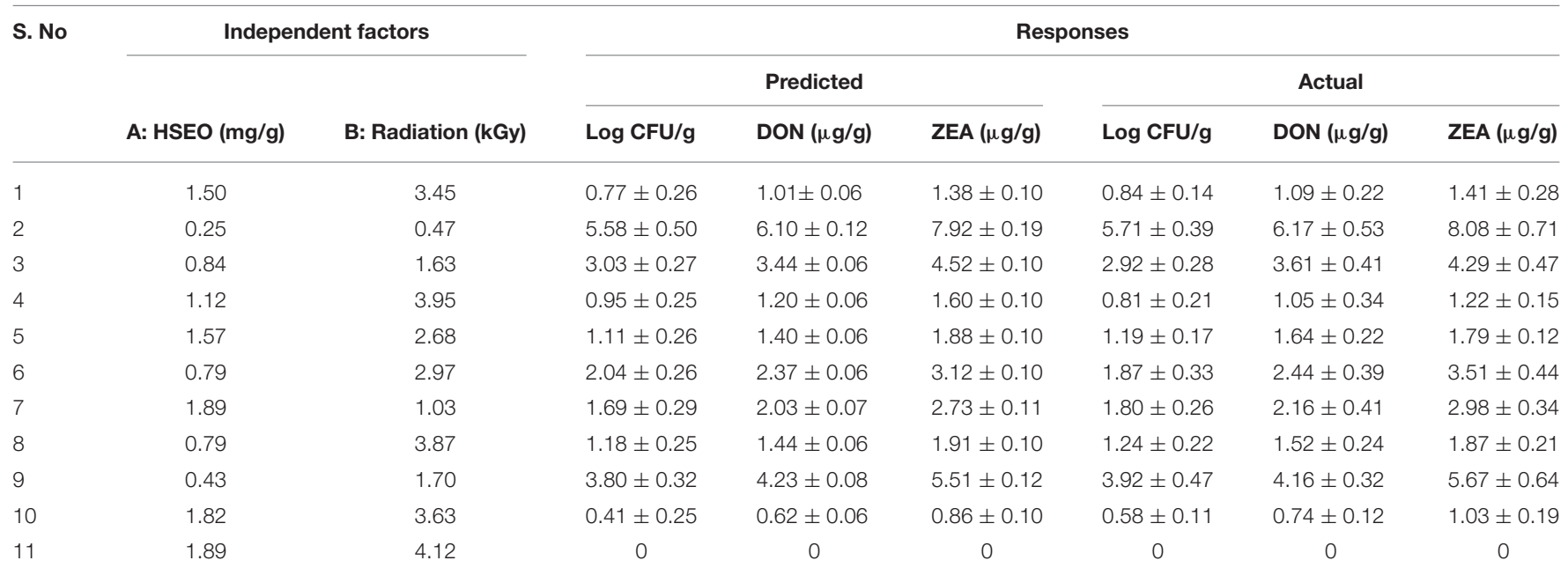


radiation treatments on growth, production of DON and ZEA by F. graminearum in maize grains was studied by CCD of RSM statistical program. The fungal growth, DON, and ZEA content were not detected at combinational treatment of $1.89 \mathrm{mg} / \mathrm{g}$ of HSEO and $4.12 \mathrm{kGy}$ of radiation. The results revealed that combination of HSEO and radiation treatments could reduce the fungal growth, DON, and ZEA content at much lower concentration than their discrete inhibitory dose. The quadratic model was found well appropriate for reductions of fungal growth (log CFU), DON, and ZEA content in maize grains. The optimized design was found statistically significant $(p<0.05)$ with larger $F$-value and adequate precision, and a smaller $p$ value. The actual data points were close to the straight line and presented good correlation regression coefficients $\left(R^{2}\right)$ for the responses. In addition, diagnostic and correlation plots, i.e., correlation matrix, normal plot residuals, Box-Cox, and actual vs. predicted plots were confirmed that optimized design was accurate and appropriate. The study concluded that optimized design could adequately represent the real interdependence of factors chosen (HSEO and radiation) for reductions of fungal growth, DON, and ZEA content. The present study suggests that combinational treatment of essential oil and radiation could be a novel promising approach for improving the shelflife and safety of food and feed matrices. As well, study accomplishes that usage of natural antifungal agents with the combination of food-processing techniques is an appropriate

\section{REFERENCES}

Adams, R. P. (2007). Identification of Essential Oil Components by Gas Chromatography/Mass Spectrometry. Carol Stream, IL: Allured Publishing Corporation.

Aiyaz, M., Thimmappa Divakara, S., Mudili, V., George Moore, G., Kumar Gupta, V., Chandra Nayaka, S., et al. (2016). Molecular diversity of seed-borne Fusarium species associated with Maize in India. Curr. Genom. 17, 132-144. doi: 10.2174/1389202917666151116213056

Akocak, P. B., Churey, J. J., and Worobo, R. W. (2015). Antagonistic effect of chitinolytic Pseudomonas and Bacillus on growth of fungal hyphae and spores of aflatoxigenic Aspergillus flavus. Food Biosci. 10, 48-58. doi: 10.1016/j.fbio.2015.01.005

Anderson, M. J., and Whitcomb, P. J. (2016). DOE Simplified: Practical Tools for Effective Experimentation. Boca Raton, FL: CRC Press.

Annunziata, L., Stramenga, A., Visciano, P., Schirone, M., De Colli, L., Colagrande, M. N., et al. (2017). Simultaneous determination of aflatoxins, T-2 and HT-2 toxins, and fumonisins in cereal-derived products by QuEChERS extraction coupled with LC-MS/MS. Anal. Bioanal. Chem. 409, 5143-5155. doi: 10.1007/s00216-017-0462-Z

Atkinson, A. C., and Donev, A. N. (1992). Optimum Experimental Designs. Oxford, UK: Oxford Science Publications.

Aziz, N. H., Ferial, M., Shahin, A. A., and Roushy, S. M. (2007). Control of Fusarium moulds and fumonisin B 1 in seeds by gamma-irradiation. Food Control. 18, 1337-1342. doi: 10.1016/j.foodcont.2005.12.013

Bernhoft, A., Torp, M., Clasen, P. E., Løes, A. K., and Kristoffersen, A. B. (2012). Influence of agronomic and climatic factors on Fusarium infestation and mycotoxin contamination of cereals in Norway. Food Addit. Contaminants 29, 1129-1140. doi: 10.1080/19440049.2012.672476

Box, G. E. P., and, Cox, D. R. (1964). An analysis of transformation (with discussion). J. R. Statist. Soc. B26, 211-252.

Calado, T., Venâncio, A., and Abrunhosa, L. (2014). Irradiation for mold and mycotoxin control: a review. Comprehens. Rev. Food Sci. Food Safety 13, 1049-1061. doi: 10.1111/1541-4337.12095 and innovative strategy to improve decontamination efficiency of food-processing techniques.

\section{AUTHOR CONTRIBUTIONS}

NK, JK, CS, KK, and VM designed and interpreted data of the work. NK, JK, CS, VG, and VM have drafted the work. All authors have approved the final version to be published.

\section{ACKNOWLEDGMENTS}

The first author is thankful to the UGC, Government of India for providing Junior Research Fellowship [File no: F. 2-14/2012(SA-I)] to pursue Ph.D. Authors are also grateful to Dr. K. Jayathilakan and Dr. M.C. Pandey, Freeze Drying and Processing Technology Division, Defence Food Research Laboratory, Mysuru, India, for providing the $\gamma$-radiation facility. The authors are also thankful to Director, DFRL, and DRDO-BU-CLS for their kind support.

\section{SUPPLEMENTARY MATERIAL}

The Supplementary Material for this article can be found online at: https://www.frontiersin.org/articles/10.3389/fmicb. 2018.01511/full\#supplementary-material

CAST (Council for Agricultural Science and Technology) (2003). Mycotoxins: Risks in Plant, Animal and Human Systems. Task Force Report No. 139, CAST, Ames, IA. 199 pp.

Chatterjee, S., Variyar, P. S., Gholap, A. S., Padwal-Desai, S. R., and Bongirwar, D. R. (2000). Effect of $\gamma$-irradiation on the volatile oil constituents of turmeric (Curcuma longa). Food Res. Int. 33, 103-106. doi: 10.1016/S0963-9969(00)00012-0

Chee, H. Y., Kim, H., and Lee, M. H. (2009). In vitro antifungal activity of limonene against Trichophyton rubrum. Mycobiology 37, 243-246. doi: 10.4489/MYCO.2009.37.3.243

Chen, Y., Zeng, H., Tian, J., Ban, X., Ma, B., and Wang, Y. (2014). Dill (Anethum graveolens L.) seed essential oil induces Candida albicans apoptosis in a metacaspase-dependent manner. Fungal Biol. 118, 394-401. doi: 10.1016/j.funbio.2014.02.004

Council of Europe. (1997). "Methods of pharmacognosy" in European. Pharmacopoeia 3, 121-122.

da Cruz Cabral, L., Pinto, V. F., and Patriarca, A. (2013). Application of plant derived compounds to control fungal spoilage and mycotoxin production in foods. Int. J. Food Microbiol. 166, 1-14. doi: 10.1016/j.ijfoodmicro.2013.05.026

Deba, F., Xuan, T. D., Yasuda, M., and Tawata, S. (2008). Chemical composition and antioxidant, antibacterial and antifungal activities of the essential oils from Bidens pilosa Linn. var. Radiata. Food Control 19, 346-352. doi: 10.1016/j.foodcont.2007.04.011

de Campos, S. X., Sanches, S. M., Falone, S. Z., and Vieira, E. M. (2004). Influence of rate dose in the degradation of the 2, 4 dichlorophenoxyacetic acid (2, 4-D) herbicide in water and methanol by gamma radiation from cobalto-60. Eclética Química 29, 41-46. doi: 10.1590/S0100-46702004000100005

Divakara, S. T., Santosh, P., Aiyaz, M., Venkata Ramana, M., Hariprasad, P., Nayaka, S. C., et al. (2014). Molecular identification and characterization of Fusarium spp. associated with sorghum seeds. J. Sci. Food Agric. 94, 1132-1139. doi: 10.1002/jsfa.6380

Du, M., Liu, Y., and Zhang, G. (2017). Interaction of aflatoxin B1 and fumonisin B1 in HepG2 cell apoptosis. Food Biosci. 20, 131-140. doi: 10.1016/j.fbio.2017.09.003 
Ferreira-Castro, F. L., Aquino, S., Greiner, R., Ribeiro, D. H. B., Reis, T. A., and Correa, B. (2007). Effects of gamma radiation on maize samples contaminated with Fusarium verticillioides. Appl. Radiat. Isotopes 65, 927-933. doi: 10.1016/j.apradiso.2007.03.011

Gao, T., Zhou, H., Zhou, W., Hu, L., Chen, J., and Shi, Z. (2016). The fungicidal activity of thymol against Fusarium graminearum via inducing lipid peroxidation and disrupting ergosterol biosynthesis. Molecules 21:E770. doi: 10.3390/molecules21060770

George, E., Kasipandi, M., Vekataramana, M., Kumar, K. N., Allen, J. A., Parimelazhagan, T., et al. (2016). In vitro anti-oxidant and cytotoxic analysis of Pogostemon mollis Benth. Bangladesh J. Pharmacol. 11, 148-158. doi: 10.3329/bjp.v11i1.24157

Ghosh, P. K., Bhattacharjee, P., and Das, S. (2017). Extension of shelf life of tuberose flowers using a combination of gamma irradiation and generally regarded as safe (GRAS) preservatives and assessment of antimicrobial potency of senesced flowers. J. Hortic. Sci. Biotechnol. 92, 130-145. doi: $10.1080 / 14620316.2016 .1234340$

Gobbo-Neto, L., and Lopes, N. P. (2007). Medicinal plants: factors of influence on the content of secondary metabolites. Quimica Nova 30, 374-381. doi: 10.1590/S0100-40422007000200026

Gonçalves, R. A., Navarro-Guillén, C., Gilannejad, N., Dias, J., Schatzmayr, D., Bichl, G., et al. (2018). Impact of deoxynivalenol on rainbow trout: growth performance, digestibility, key gene expression regulation and metabolism. Aquaculture 490, 362-372. doi: 10.1016/j.aquaculture.2018. 03.001

Haddad, M., Herent, M. F., Tilquin, B., and Quetin-Leclercq, J. (2007). Effect of gamma and e-beam radiation on the essential oils of Thymus vulgaris thymoliferum, Eucalyptus radiata, and Lavandula angustifolia. J. Agric. Food Chem. 55, 6082-6086. doi: 10.1021/jf063540+

Hossain, F., Follett, P., Vu, K. D., Salmieri, S., Senoussi, C., and Lacroix, M. (2014). Radiosensitization of Aspergillus niger and Penicillium chrysogenum using basil essential oil and ionizing radiation for food decontamination. Food Control 45, 156-162. doi: 10.1016/j.foodcont.2014.04.022

Hyldgaard, M., Mygind, T., and Meyer, R. L. (2012). Essential oils in food preservation: mode of action, synergies, and interactions with food matrix components. Front. Microbiol. 3:12. doi: 10.3389/fmicb.2012.00012

IARC. (1999). Overall Evaluations of Carcinogenicity to Humans. International Agency for Research on Cancer. IARC Monographs 1-73, 1-36.

IAEA. (2001). "Consumer acceptance and market development of irradiated food in Asia and the Pacific. IAEA TECDOC-1219," in Proceedings of the Final Research Co-Ordination Meeting (Leuven), 24-28.

Iram, W., Anjum, T., Iqbal, M., Ghaffar, A., and Abbas, M. (2016). Structural elucidation and toxicity assessment of degraded products of Aflatoxin B1 and B2 by aqueous extracts of Trachyspermum ammi. Front. Microbiol. 7:346. doi: $10.3389 /$ fmicb. 2016.00346

Jeong, R. D., Chu, E. H., Shin, E. J., Lee, E. S., Kwak, Y. S., and Park, H. J. (2015). Antifungal effect of gamma irradiation and sodium dichloroisocyanurate against Penicillium expansum on pears. Lett. Appl. Microbiol. 61, 437-445. doi: 10.1111/lam.12466

Ji, F., Xu, J., Liu, X., Yin, X., and Shi, J. (2014). Natural occurrence of deoxynivalenol and zearalenone in wheat from jiangsu province, China. Food Chem. 157, 393-397. doi: 10.1016/j.foodchem.2014.02.058

Joshi, S., Chanotiya, C. S., Agarwal, G., Prakash, O., Pant, A. K., and Mathela, C. S. (2008). Terpenoid compositions, and antioxidant and antimicrobial properties of the rhizome essential oils of different Hedychium species. Chem. Biodivers. 5, 299-309. doi: 10.1002/cbdv.200890027

Kalagatur, N. K., Ghosh, O. S. N., Sundararaj, N., and Mudili, V. (2018a). Antifungal activity of chitosan nanoparticles encapsulated with Cymbopogon martinii essential oil on plant pathogenic fungi Fusarium graminearum. Front. Pharmacol. 9:610. doi: 10.3389/fphar.2018.00610

Kalagatur, N. K., Kamasani, J. R., Mudili, V., Krishna, K., Chauhan, O. P., and Sreepathi, M. H. (2018b). Effect of high pressure processing on growth and mycotoxin production of Fusarium graminearum in maize. Food Biosci. 21, 53-59. doi: 10.1016/j.fbio.2017.11.005

Kalagatur, N. K., Karthick, K., Allen, J. A., Nirmal Ghosh, O. S., Chandranayaka, S., Gupta, V. K., et al. (2017). Application of activated carbon derived from seed shells of jatropha curcas for decontamination of zearalenone mycotoxin. Front. Pharmacol. 8:760. doi: 10.3389/fphar.2017.00760
Kalagatur, N. K., Mudili, V., Siddaiah, C., Gupta, V. K., Natarajan, G., Sreepathi, M. H., et al. (2015). Antagonistic activity of Ocimum sanctum L. essential oil on growth and zearalenone production by Fusarium graminearum in maize grains. Front. Microbiol. 6:892. doi: 10.3389/fmicb.2015.00892.

Kanapitsas, A., Batrinou, A., Aravantinos, A., Sflomos, C., and Markaki, P. (2016). Gamma radiation inhibits the production of Ochratoxin A by Aspergillus carbonarius. Development of a method for OTA determination in raisins. Food Biosci. 15, 42-48. doi: 10.1016/j.fbio.2016.05.001

Koul, S., Raina, V., and Sharma, S. K. (2005). Conservation and propagation of high altitude medicinal and aromatic plant: Hedychium spicatum. J. Plant Biochem. Biotechnol. 14, 57-59. doi: 10.1007/BF03263227

Kretschmer, M., Leroch, M., Mosbach, A., Walker, A. S., Fillinger, S., Mernke, D., et al. (2009). Fungicide-driven evolution and molecular basis of multidrug resistance in field populations of the grey mould fungus Botrytis cinerea. PLoS Pathogens 5:e1000696. doi: 10.1371/journal.ppat.1000696

Kumar, K. N., Venkataramana, M., Allen, J. A., Chandranayaka, S., Murali, H. S., and Batra, H. V. (2016). Role of Curcuma longa L. essential oil in controlling the growth and zearalenone production of Fusarium graminearum. LWT-Food Sci. Technol. 69, 522-528. doi: 10.1016/j.lwt.2016.02.005

Lacroix, M., and Ouattara, B. (2000). Combined industrial processes with irradiation to assure innocuity and preservation of food products-a review. Food Res. Int. 33, 719-724. doi: 10.1016/S0963-9969(00)00085-5

Le Caër, S. (2011). Water radiolysis: influence of oxide surfaces on $\mathrm{H}_{2}$ production under ionizing radiation. Water 3, 235-253. doi: 10.3390/w3010235

Lima, K. D. S. C., e Souza, L. B., de Oliveira Godoy, R. L., França, T. C. C., and dos Santos Lima, A. L. (2011). Effect of gamma irradiation and cooking on cowpea bean grains (Vigna unguiculata L. Walp). Radiat. Phys. Chem. 80, 983-989. doi: 10.1016/j.radphyschem.2011.04.011

Maherani, B., Hossain, F., Criado, P., Ben-Fadhel, Y., Salmieri, S., and Lacroix, M. (2016). World market development and consumer acceptance of irradiation technology. Foods 5:79. doi: 10.3390/foods5040079

Mallmann, C. A., Dilkin, P., Mallmann, A. O., Oliveira, M. S., Adaniya, Z. N. C., and Tonini, C. (2017). Prevalence and levels of deoxynivalenol and zearalenone in commercial barley and wheat grain produced in Southern Brazil: an eight-year (2008 to 2015) summary. Trop. Plant Pathol. 42, 146-152. doi: $10.1007 /$ s40858-017-0152-6

Mishra, S., Ansari, K. M., Dwivedi, P. D., Pandey, H. P., and Das, M. (2013). Occurrence of deoxynivalenol in cereals and exposure risk assessment in Indian population. Food Control 30, 549-555. doi: 10.1016/j.foodcont.2012. 07.041

Mudili, V., Siddaih, C. N., Nagesh, M., Garapati, P., Naveen Kumar, K., Murali, H. S., et al. (2014). Mould incidence and mycotoxin contamination in freshly harvested maize kernels originated from India. J. Sci. Food Agric. 94, 2674-2683. doi: $10.1002 /$ jsfa.6608

Muniyandi, K., George, E., Mudili, V., Kalagatur, N. K., Anthuvan, A. J., Krishna, K., et al. (2017). Antioxidant and anticancer activities of Plectranthus stocksii Hook. f. leaf and stem extracts. Agric. Nat. Res. 51, 63-73. doi: 10.1016/j.anres.2016.07.007

Muthulakshmi, S., Maharajan, K., Habibi, H. R., Kadirvelu, K., and Venkataramana, M. (2018). Zearalenone induced embryo and neurotoxicity in zebrafish model (Danio rerio): role of oxidative stress revealed by a multi biomarker study. Chemosphere 198, 111-121. doi: 10.1016/j.chemosphere.2018.01.141

Myers, R. H., Montgomery, D. C., and Anderson-Cook, C. M. (2016). Response Surface Methodology: Process and Product Optimization Using Designed Experiments. Hoboken, NJ: John Wiley \& Sons.

Pasquali, M., Beyer, M., Logrieco, A., Audenaert, K., Balmas, V., Basler, R., et al. (2016). A European database of Fusarium graminearum and F. culmorum trichothecene genotypes. Front. Microbiol. 7:406 doi: $10.3389 /$ fmicb. 2016.00406

Pawar, V. C., and Thaker, V. S. (2006). In vitro efficacy of 75 essential oils against Aspergillus niger. Mycoses 49, 316-323. doi: 10.1111/j.1439-0507.2006.01241.x

Pitt, J. I., and Hockings, A. D. (2009). Fungi and Food spoilage, 3rd Edn. New York, NY: Springer.

Ramana, M. V., Balakrishna, K., Murali, H. C. S., and Batra, H. V. (2011). Multiplex PCR-based strategy to detect contamination with mycotoxigenic Fusarium species in rice and fingermillet collected from southern India. J. Sci. Food Agric. 91, 1666-1673. doi: 10.1002/jsfa.4365 
Ramsdale, M. (2008). Programmed cell death in pathogenic fungi. Biochim. Biophys. Acta 1783, 1369-1380. doi: 10.1016/j.bbamcr.2008.01.021

Reddy, K. E., Lee, W., young Jeong, J., Lee, Y., Lee, H. J., Kim, M. S., et al. (2018). Effects of deoxynivalenol-and zearalenone-contaminated feed on the gene expression profiles in the kidneys of piglets. Asian-australas. J. Anim. Sci. 31, 138-148. doi: 10.5713/ajas.17.0454

Reddy, K. J., Jayathilakan, K., and Pandey, M. C. (2015). Effect of ionizing radiation on the protein and lipid quality characteristics of mutton kheema treated with rice bran oil and sunflower oil. Radiat. Phys. Chem. 117, 217-224. doi: 10.1016/j.radphyschem.2015.09.002

Sabulal, B., George, V., Dan, M., and Pradeep, N. S. (2007). Chemical composition and antimicrobial activities of the essential oils from the rhizomes of four Hedychium species from South India. J. Essent. Oil Res. 19, 93-97. doi: 10.1080/10412905.2007.9699237

Schirone, M., Visciano, P., Tofalo, R., and Suzzi, G. (2016). Biological hazards in food. Front. Microbiol. 7:2154. doi: 10.3389/fmicb.2016.02154

Schumann, B., Winkler, J., Mickenautsch, N., Warnken, T., and Dänicke, S. (2016). Effects of deoxynivalenol (DON), zearalenone (ZEN), and related metabolites on equine peripheral blood mononuclear cells (PBMC) in vitro and background occurrence of these toxins in horses. Mycotoxin Res. 32, 153-161. doi: 10.1007/s12550-016-0250-1

Sellamani, M., Kalagatur, N. K., Siddaiah, C., Mudili, V., Krishna, K., Natarajan, G., et al. (2016). Antifungal and zearalenone inhibitory activity of Pediococcus pentosaceus isolated from dairy products on Fusarium graminearum. Front. Microbiol. 7:890. doi: 10.3389/fmicb.2016.00890

Sirocchi, V., Devlieghere, F., Peelman, N., Sagratini, G., Maggi, F., Vittori, S., et al. (2017). Effect of Rosmarinus officinalis L. essential oil combined with different packaging conditions to extend the shelf life of refrigerated beef meat. Food Chem. 221, 1069-1076. doi: 10.1016/j.foodchem.2016.11.054

Tian, J., Ban, X., Zeng, H., He, J., Chen, Y., and Wang, Y. (2012). The mechanism of antifungal action of essential oil from dill (Anethum graveolens L.) on Aspergillus flavus. PLoS ONE 7:e30147. doi: 10.1371/journal.pone.00 30147

Tima, H., Berkics, A., Hannig, Z., Ittzés, A., Kecskésné Nagy, E., MohácsiFarkas, C., et al. (2018). Deoxynivalenol in wheat, maize, wheat flour and pasta: surveys in Hungary in 2008-2015. Food Addit. Contamin. 11, 37-42. doi: 10.1080/19393210.2017.1397061

Tralamazza, S. M., Bemvenuti, R. H., Zorzete, P., de Souza Garcia, F., and Corrêa, B. (2016). Fungal diversity and natural occurrence of deoxynivalenol and zearalenone in freshly harvested wheat grains from Brazil. Food Chem. 196, 445-450. doi: 10.1016/j.foodchem.2015.09.063

Udomkun, P., Wiredu, A. N., Nagle, M., Bandyopadhyay, R., Müller, J., and Vanlauwe, B. (2017). Mycotoxins in Sub-Saharan Africa: present situation, socio-economic impact, awareness, and outlook. Food Control 72, 110-122. doi: 10.1016/j.foodcont.2016.07.039

Usta, J., Kreydiyyeh, S., Knio, K., Barnabe, P., Bou-Moughlabay, Y., and Dagher, S. (2009). Linalool decreases HepG2 viability by inhibiting mitochondrial complexes I and II, increasing reactive oxygen species and decreasing ATP and GSH levels. Chem. Biol. Interact. 180, 39-46. doi: 10.1016/j.cbi.2009.02.012
Van Vuuren, S. F., and Viljoen, A. M. (2007). Antimicrobial activity of limonene enantiomers and 1, 8-cineole alone and in combination. Flavour Fragr. J. 22, 540-544. doi: 10.1002/ffj. 1843

Velluti, A., Sanchis, V., Ramos, A. J., Egido, J., and Mari, S. (2003). Inhibitory effect of cinnamon, clove, lemongrass, oregano and palmarose essential oils on growth and fumonisin B 1 production by Fusarium proliferatum in maize grain. Int. J. Food Microbiol. 89, 145-154. doi: 10.1016/S0168-1605(03)00116-8

Venkataramana, M., Nayaka, S. C., Anand, T., Rajesh, R., Aiyaz, M., Divakara, S. T., et al. (2014). Zearalenone induced toxicity in SHSY-5Y cells: the role of oxidative stress evidenced by $\mathrm{N}$-acetyl cysteine. Food Chem. Toxicol. 65, 335-342. doi: 10.1016/j.fct.2013.12.042

Vilela, G. R., de Almeida, G. S., D'Arce, M. A. B. R., Moraes, M. H. D., Brito, J. O., da Silva, M. F. D. G., et al. (2009). Activity of essential oil and its major compound, 1, 8-cineole, from Eucalyptus globulus Labill. against the storage fungi Aspergillus flavus Link and Aspergillus parasiticus Speare. J. Stored Prod. Res. 45, 108-111. doi: 10.1016/j.jspr.2008.10.006

Whitcomb, P. J., and Anderson, M. J. (2004). RSM Simplified: Optimizing Processes Using Response Surface Methods for Design of Experiments. Boca Raton, FL: CRC Press.

Wilson, M. D., Stanley, R. A., Eyles, A., and Ross, T. (2017). Innovative processes and technologies for modified atmosphere packaging of fresh and fresh-cut fruits and vegetables. Crit. Rev. Food Sci. Nutr. 1-12. doi: 10.1080/10408398.2017.1375892

Wilson, W., Dahl, B., and Nganje, W. (2018). Economic costs of fusarium head blight, scab and deoxynivalenol. World Mycotoxin J. 11, 291-302. doi: 10.3920/WMJ2017.2204

Wu, L., Qiu, L., Zhang, H., Sun, J., Hu, X., and Wang, B. (2017). Optimization for the production of deoxynivalenol and zearalenone by Fusarium graminearum using response surface methodology. Toxins 9:57. doi: 10.3390/toxins 9020057

Xu, L. L., Wen, Y. Q., Liu, Y. L., and Ma, Y. X. (2018). Occurrence of deoxynivalenol in maize germs from North China Plain and the distribution of deoxynivalenol in the processed products of maize germs. Food Chem. 198, 111-121. doi: 10.1016/j.foodchem.2018.05.111

Zinedine, A., Soriano, J. M., Molto, J. C., and Manes, J. (2007). Review on the toxicity, occurrence, metabolism, detoxification, regulations and intake of zearalenone: an oestrogenic mycotoxin. Food Chem. Toxicol. 45, 1-18. doi: 10.1016/j.fct.2006.07.030

Conflict of Interest Statement: The authors declare that the research was conducted in the absence of any commercial or financial relationships that could be construed as a potential conflict of interest.

Copyright () 2018 Kalagatur, Kamasani, Siddaiah, Gupta, Krishna and Mudili. This is an open-access article distributed under the terms of the Creative Commons Attribution License (CC BY). The use, distribution or reproduction in other forums is permitted, provided the original author(s) and the copyright owner(s) are credited and that the original publication in this journal is cited, in accordance with accepted academic practice. No use, distribution or reproduction is permitted which does not comply with these terms. 